\title{
Markups in a dual labour market: the case of the Netherlands
}

The choice of the free input may explain at least some of the discrepancies in the literature.
Stable markups in the Netherlands 2006-2016. 


\title{
Markups in a dual labour market: the case of the Netherlands
}

\author{
Gerrit Hugo van Heuvelen* Leon Bettendorf ${ }^{\dagger} \quad$ Gerdien Meijerink ${ }^{\ddagger}$
}

February 11, 2020

\begin{abstract}
We follow the production function approach to assess markups, which requires the estimation of the output elasticity of a free input. In the basic setup we estimate a structural value added production function, using temporary contract hours as free input. We find rather stable markups in the Netherlands in the period 2006-2016. We show that extending the free variable incorrectly with fixed contract hours results in an increasing markup. Findings are robust to an alternative setup, in which a gross output function is specified and materials are used as free input. Implications for applied work and policy are discussed.
\end{abstract}

Keywords: Markups, free variable, flexible contract labour

\footnotetext{
${ }^{*}$ CPB Netherlands Bureau for Economic Policy Analysis. E-mail: G.H.van.Heuvelen@cpb.nl.

${ }^{\dagger}$ CPB Netherlands Bureau for Economic Policy Analysis. Corresponding author: CPB, P.O. Box 80510, 2508 GM, The Hague, The Netherlands. E-mail: L.J.H.Bettendorf@cpb.nl.

${ }^{\ddagger}$ CPB Netherlands Bureau for Economic Policy Analysis. E-mail: G.W.Meijerink@cpb.nl.

We thank Hugo de Bondt, Jan De Loecker, Robert Inklaar, Daan Freeman and CPB colleagues for all their constructive comments. The data used for our analysis is confidential data and only available for personally registered users of Statistics Netherlands (CBS-remote access). All remaining errors are ours.
} 


\section{Introduction}

An expanding body of research finds a sharp increase in the average markups in the US and Europe (including the Netherlands), which is driven by firms located at the top of the markup distribution (i.e. De Loecker and Eeckhout, 2017, 2018a; Calligaris et al., 2018; Diez et al., 2018). Other studies find that markups in the US and Europe have increased only moderately or even remained more or less stable (i.e. Traina, 2018; De Loecker et al., 2018; Hall, 2018; Cavalleri et al., 2019; Weche and Wambach, 2018). These differing results have triggered a discussion on methodology (see e.g. Basu, 2019; Flynn et al., 2019). A key issue is the choice of the free input in the production function approach, used in many markup studies, as it determines the trend of the markup (Traina, 2018; Karabarbounis and Neiman, 2018).

The main aim of this paper is to show that the choice of the free input is crucial, and may explain at least some of the discrepancies in the findings in the recent literature. We illustrate this with the case of the Netherlands, which has a large share of flexible work arrangements and temporary labour contracts as well as fixed contracts. This duality enables us to pursue a novel approach by using only the temporary labour hours for the free variable. In addition, we address the identification problems by applying the solutions proposed in De Loecker and Scott (2016) and Gandhi et al. (2017). We estimate the production function with serially correlated input prices included as extra instruments, which tackles the identification issue. In addition to estimating a Cobb-Douglas (CD) function, we report results for the more flexible Translog production function. Finally, we touch on the question what consolidation level of the accounts of the firm is most appropriate, national or international.

Our results show that when we take the duality of the Dutch labour market into account and use as free input the labour of temporary workers input in hours, we obtain stable markups in the Netherlands for the period 2006-2016. There is some heterogeneity in the results, with firms located at the upper end of the markup distribution increasing their markups. However, this increase is far below the magnitude found in other papers and is not driven by large firms. We demonstrate that extending the free variable incorrectly with fixed contract hours results in an increasing markup. This underscores the need to take into account the institutional features of a country in measuring markups. Second, we find that alternative setups produce fairly similar results as our preferred setup. Our preferred setup includes as free input temporary labour and its output elasticity results from estimating a structural value added production function. In an alternative setup we combine a gross output function and materials as free input. Third, we show that a key issue in using firm-level data is the consolidation level of the accounts of the firm, although a priori, the preferred level of consolidation is not clear.

We use the case of the Netherlands, as it enables us to follow the advice of Basu (2019) 
that the production function is best estimated using a single, distinct measure of physical input as free variable. In the Netherlands, temporary contract workers can be hired or fired more easily; their input will thus adjust more quickly to changes in output and hence is a better free variable. The OECD publishes indicators of the strictness of regulation on dismissals for temporary and regular contracts ()OECD, 2020b). The latest indicator (for 2013) shows a large gap for the Netherlands between regular and temporary contracts (2.82 versus 0.94 ), indicating that it is easier to hire and fire workers on a temporary contract than a regular contract. By contrast, France has stricter regulation for temporary contracts (3.63) than regular contracts (2.38). The US has one of the lowest restrictions on firing employees on regular contracts (1.10) and temporary contracts (0.25).

The share of temporary contract employees in the Netherlands is one of the highest in the OECD. With a share of $20.8 \%$ in 2016 it is almost twice as high as the OECD average of $11.8 \%$ (OECD, 2020a). ${ }^{1}$ We see in Figure 1 that employees with a temporary contract leave the workforce during downturns and enter during upswings of the Dutch economy, thus reflecting the lower hiring and firing costs of temporary contracts.

Figure 1: Growth rate of hours worked per employee with a flexible contract

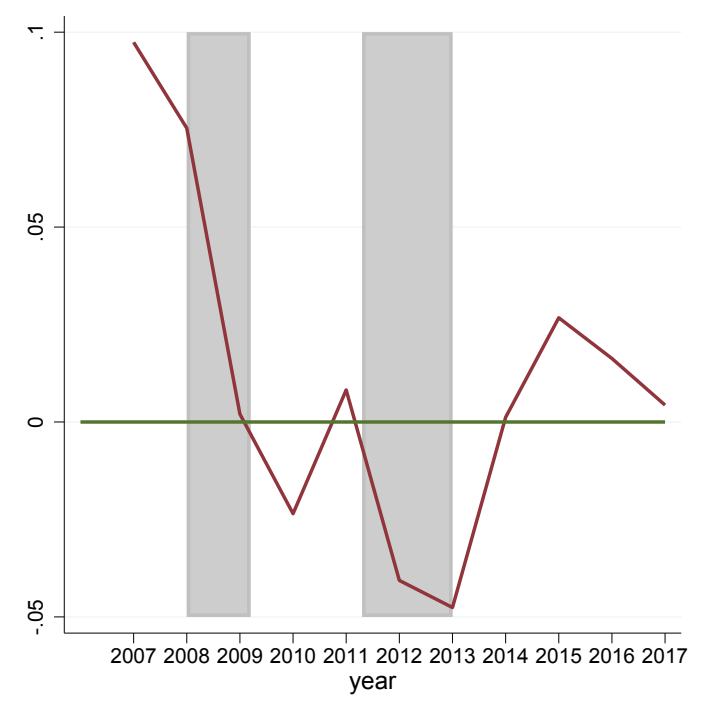

Notes: The grey bloks indicate reccessions as identified by CEPRs Euro Area Business Cycle Dating Committee. The hours worked are obtained from the Polisbus and the number of employees with a flexible contract is obtained from the CBS Statline.

The rest of the paper is organized as follows. The next section overviews the empirical

\footnotetext{
${ }^{1}$ Other countries that have a relatively large dual labour market are Spain, Portugal, Poland, Finland and South Korea.
} 
literature. Section 3 on the production function approach discusses methodological issues and choices. Section 4 describes the data and the construction of the variables. Section 5 provides empirical results and section 6 concludes.

\section{Literature overview}

An overview of the recent literature provides various applications of the production function approach to estimate markups, starting in the US. It shows that markets in the US have become more concentrated and competition has weakened since the 1980s (see Gutiérrez and Philippon, 2016, 2017). Furthermore, De Loecker et al. (2020) find that the markups of publicly traded firms have risen from $21 \%$ in 1980 to $61 \%$ in 2016 , especially from 1980 to 2000 and after 2011. The increase is exclusively due to firms located in the top decile of the revenue weighted markup distribution. Azar et al. (2017) find evidence that labour demand in the US is highly concentrated, giving firms buying power which leads to declining posted wages. Barkai (2017) documents that the decrease in the labour share in value added in the US was combined with an increasing profit share over the last thirty years. In sum, the evidence seems to indicate a rise in "superstar firms" in the US, which is often associated with a decline in competition, but may also be a result of consumers becoming more sensitive to quality-adjusted prices. an argument made by Autor et al. (2017).

The situation in Europe might be different with markets that are less concentrated, firms with lower excess profits and lower regulatory barriers to entry (see Gutiérrez and Philippon, 2018). European markets may, therefore, be more competitive than their American counterparts. Nonetheless, De Loecker and Eeckhout (2018a) show that markups have also risen in Europe. This is the only study that includes results for the Netherlands. The Dutch markup is estimated to have increased from $5 \%$ in 1980 to $52 \%$ in 2016 . This increase of $47 \%$ points is, by all standards, rather large but remains below the European average increase of $66 \%$ points, which is similar to the estimated increase for the US. It is important to note that most of this increase happened, certainly for the Netherlands, after $2012 .^{2}$

Diez et al. (2018) find similar results for advanced economies (including the Netherlands) as De Loecker and Eeckhout (2018a), using the same dataset. ${ }^{3}$ They estimate a GDP-weighted average markup and find increasing markups of 39\% since 1980 for advanced economies. Although no markups are shown for individual countries other than the US, they state that the

\footnotetext{
${ }^{2}$ In section 5 , we discuss differences in the setup that might explain the difference between the results that De Loecker and Eeckhout (2018a) obtain for the Netherlands and our results.

${ }^{3}$ Diez et al. (2018) estimate the output elasticity of each industry for two separate periods and by pooling the firms of all countries. De Loecker and Eeckhout (2018a) use the output elasticities estimated for the US in De Loecker and Eeckhout (2017).
} 
markups in Europe have increased mainly since the 2000s. They show that the distribution of markups, which are highly concentrated around 1 in the 1980s, becomes less concentrated in 2016 as the right tail gains more mass. ${ }^{4}$ The increase in markups is therefore driven by high markup firms.

Calligaris et al. (2018) find that the average markup increased over 2001-2014 for 26 countries (21 OECD countries, including the Netherlands). It is important to note that they report the unweighted average $(\log )$ markup and not revenue weighted markups, as in the other papers. The average increase is smaller, around $6 \%$ over a shorter time period of thirteen years, and markups only start increasing after 2005 . This trend is driven by firms at the top decile of the unweighted markup distribution with an increase in markups of $25 \%$. The authors also find that digital intensive sectors have higher markups than other sectors.

Weche and Wambach (2018) analyse the markup for seventeen EU countries from 2007 to 2015. Contrary to the previous papers, they find that the average weighted markup hardly increased over this time period. The markup first drops during the crisis, after which it increases post-crisis, although in 2015 it has still not reached its pre-crisis level. This is in sharp contrast to the US where the markup quickly recovered to reach its pre-crisis level before 2011 (see De Loecker and Eeckhout, 2017). The difference could be attributed to the fact that Europe was hit by a second crisis (European Debt Crisis). Weche and Wambach (2018) state that deleting the bottom and top $1 \%$ of the markup distribution is crucial for their average weighted markup result, as not deleting these observations leads to increasing markups after 2011 that exceed their pre-crisis level by 2014. This finding raises concern since the focus is on the weighted average markup, which is sensitive to outliers, and the rise in markups in other papers is caused by the top decile. Outlier strategies might therefore be crucial for obtained results. They conclude (p16): "As markup figures for Europe are very much different from those in the United States, one should be cautious by transferring arguments in this debate from the United States to Europe".

The study most closely related to our work is that of De Loecker and Eeckhout (2018b), which estimates the markup of firms in Belgium, using a firm-level dataset that includes all non-financial, private firms between 1980 and 2016. The study finds no evidence of rising markups after the early 2000s. The authors stress the importance of using a free variable in estimating markups and distinguish between service material inputs and goods material inputs, arguing that the latter is free and the former is more fixed. They find decreasing markups for total material inputs, as the share of service material costs increases over time. When only goods material inputs are used as free input, markups rise for the top of the distribution.

\footnotetext{
${ }^{4}$ In the markup distribution of 1980 , values higher than 3 do not exist, while in 2016, the distribution still has mass up to the value of 10 . This indicates the rise of extreme markups or measurement errors.
} 
We make three general remarks on the empirical studies. First, the differences in weighting, time period, sample, and presentation of results render difficult a comparison between studies. However, many studies claim to find similar results, increasing markups driven by the high markup firms. Increasing markups in the top decile of an unweighted distribution do not have the same implications as in the top decile of a weighted markup distribution. In the weighted case, large firms are driving the results, while this is not true for the unweighted case (as in Calligaris et al., 2018).

Second, Calligaris et al. (2018) rightfully raise the question whether it are the same firms that charges high markups over time. The superstar firm hypothesis implies some sort of persistence, as firms that benefit from globalization and technological progress remain the most productive ones (see Van Reenen, 2018). If it is found that different firms charge high markups over time, it is less clear what rising markups in the top decile really indicate. We will show that often the same firms charge high markups when moving from one year to the next.

Finally, an increase in markups does not per definition imply higher profits. Karabarbounis and Neiman (2018) argue that increasing markups might be caused by a rise in fixed costs. A higher markup might be needed to recover higher fixed costs. However, De Loecker and Eeckhout (2018a) and Barkai (2017) contest this claim by showing that the increased markups are associated with higher profits and market values of US firms. Our data also show that markups are positively correlated with profit rates, indicating that higher markups are not solely driven by fixed costs.

\section{Methodology}

The production function approach to measure markups is based on Hall (1988) and is further developed by De Loecker and Warzynski (2012). The application to US firms by De Loecker and Eeckhout (2017) inspired several authors to comment on the strong and weak points of the approach and to suggest improvements. In this section we describe the methodology of the production function approach followed by a briefly review of the literature with the goal to adopt the best practices.

The production function approach is based on the assumption that firms minimize costs for inputs that are free of adjustment costs, so called free inputs. Therefore, at least one free input must be present in the production function. Generally, labour or intermediate inputs are used as free input. The markup is defined as the ratio between output price $\left(p_{i t}\right)$ over its marginal cost $\left(c_{i t}\right)$. The standard first order condition with respect to the free input $X$ is 


$$
p_{i t}^{X}=\lambda_{i t} F_{X, i t}
$$

where $p_{i t}^{X}$ denotes the cost price; $F_{X, i t}$ the marginal productivity and the Lagrange multiplier $\lambda_{i t}$ is interpreted as the marginal cost. Rewriting this condition gives that the markup $\left(\mu_{i t}\right)$ equals the ratio between the output elasticity $\left(\theta_{i t}^{X}\right)$, and the cost of the free input as a share of the firms revenue $\left(C_{i t} / S_{i t}^{X}\right)$, or:

$$
\mu_{i t}=\frac{p_{i t}}{c_{i t}}=\theta_{i t}^{X} \frac{S_{i t}}{C_{i t}^{X}}
$$

Both the costs and the revenues are directly observed in the data, but the output elasticity needs to be estimated. Before we explain this estimation, we want to stress that most studies face a data limitation. The methodology was developed for firms for which the quantity of production is observed. However, since data do normally not include the quantities that the firm produces, revenues are instead deflated using an output price that is not firm-specific. As a consequence, the estimate of the markup level is potentially biased and therefore should be interpreted with caution (De Loecker and Warzynski, 2012). Fortunately, the methodology is still informative about the changes in markups over time. Next, after sketching the estimation approaches found in the literature, we discuss the two setups we have applied.

\subsection{Estimating the output elasticity}

The output elasticity is derived from a production function, which is estimated using semiparametric techniques (see Wooldridge, 2009; Ackerberg et al., 2015). The key problem for identifying the production function is that a firm's productivity is transmitted to the firm's optimal choice of inputs, giving rise to an endogeneity issue labelled transmission bias in the production function literature. The structural estimation literature (Olley and Pakes, 1996; Levinsohn and Petrin, 2003; Ackerberg et al., 2015) uses lagged input variables as a source of identifying variation. However, this requires that all the inputs in the production function are subject to adjustment frictions, since the variation caused by these frictions is the source of identification of elasticities (see Ackerberg et al., 2015). Gandhi et al. (2017) and Flynn et al. (2019) show that this identification strategy fails in the presence of a free input, i.e. inputs that have no adjustment frictions. One of the solutions, which we adopt in this paper, is finding an instrument for the free input (see Gandhi et al., 2017).

Four approaches are used to estimate output elasticities in the markup literature. The first approach, applied in De Loecker and Eeckhout (2018a) and Diez et al. (2018), estimates the production function $Q_{i t}=F\left(L_{i t}+M_{i t}, K_{i t}\right)$, where $Q$ denotes gross output, $L$ labour, $M$ materials and $K$ capital. Due to data constraints, these authors use the cost of goods sold 
as free variable, which contains both material and labour inputs. By summing materials and labour costs, it is assumed that materials and labour are perfect substitutes. The assumption that labour is part of the free variable is less likely to hold for many European countries as labour is subject to higher adjustment costs. If both materials and labour are indeed free inputs, both should lead to identical markup patterns. In section 5.2 we show that this is not the case, which gives reason to believe that total labour (i.e. the sum of fixed and temporary contract hours) is not a free input in the Netherlands.

The second approach, applied in De Loecker and Warzynski (2012) and Weche and Wambach (2018), estimates a restricted profit production function: $Q_{i t}-M_{i t}=F\left(L_{i t}, K_{i t}\right)$. Material inputs are subtracted from gross output giving value added as dependent variable. Therefore, only coefficients for labour and capital are estimated. This approach also assumes that labour is a free input, which is not the case.

The third approach, applied in Calligaris et al. (2018) and De Loecker and Eeckhout (2018b), estimates the gross output production function $Q_{i t}=F\left(L_{i t}, M_{i t}, K_{i t}\right)$. Although this avoids the previously raised problems, the gross output production function faces identification issues, as demonstrated by Gandhi et al. (2017) and Ackerberg et al. (2015). A solution to the identification problem, applied in Doraszelski and Jaumandreu (2013) and De Loecker and Scott (2016), is to include wages as an instrument, i.e. a serially correlated input price that varies across producers.

The final approach, applied in De Loecker and Scott (2016), considers a structural value added (SVA) production function, which is assumed to be Leontief in value added and materials: $Q_{i t}=\min \left(F\left(L_{i t}, K_{i t}\right), M_{i t}\right)$. Both De Loecker and Scott (2016) and Ackerberg et al. (2015) caution against the use of the gross output and restricted profit value added production function. In fact, Ackerberg et al. (2015) state that only the structural value added production function should be used due to identification issues. De Loecker and Scott (2016) find when comparing gross output, restricted profit and structural value added production functions, that the latter leads to the most plausible estimation of markups for the US brewing industry. ${ }^{5}$ Labour is the free variable but the calculation of the markup needs a correction for materials (see De Loecker and Scott, 2016). ${ }^{6}$

\footnotetext{
${ }^{5}$ De Loecker and Scott (2016) find that the SVA markups are also very similar to the markups obtained using the demand side approach (i.e Berry et al., 2004).

${ }^{6}$ In the Leontief case marginal product is only well-defined when both labour and materials are increased. Accordingly, the correct markup $\left(\mu_{c o r}\right)$ can be obtained by applying the following correction to the markup $(\mu)$ : $\mu_{\text {cor }}=\frac{1}{\mu^{-1}+C_{i t}^{M} / S_{i t}}$, where $C_{i t}^{M} / S_{i t}$ is the cost share of materials.
} 


\subsection{The setups applied}

We apply two main setups. In the first setup we estimate a structural value added production function. We construct a dataset that makes a distinction between hours worked by employees with a fixed and temporary contract, and corresponding wage costs. We use the temporary contract hours as free variable. The labour input is measured in hours, as advocated by Basu (2019). The Cobb-Douglas production function is (lower case letters denote logged variables):

$$
q_{i t}=\beta_{0}+\beta_{k} k_{i t}+\beta_{f i x} l_{i t}^{f i x}+\beta_{t e m p} l_{i t}^{t e m p}+\varepsilon_{i t}
$$

where labour hours are split up into a temporary and fixed contract component

$$
l_{i t}=l_{i t}^{f i x}+l_{i t}^{t e m p}
$$

However, this function suffers from the same identification problem as the gross output production function and the free variable should be instrumented. We therefore add the average wage of temporary employees and the average wage of all employees as instruments. The output elasticity of the free input is derived as:

$$
\theta_{i t}^{t e m p}=\frac{\partial q_{i t}}{\partial l_{i t}^{t e m p}}=\beta_{t e m p}
$$

This shows that, in the case of the Cobb-Douglas production function, the output elasticity is constant for all firms, implying that the variation of the markup over time is solely driven by the cost share of the free input. A Cobb-Douglas production function gives the same variation over time irrespective of the estimation method used to obtain the output elasticity.

An estimation of a Translog specification is added for robustness since it allows for a firmspecific output elasticity and the resulting variation of the markup over time is not equal for different estimation methods. The second order Translog production function is specified as:

$$
\begin{aligned}
q_{i t}= & \beta_{0}+\beta_{k} k_{i t}+\beta_{f i x} l_{i t}^{f i x}+\beta_{t e m p} l_{i t}^{t e m p}+\beta_{k k} k_{i t}^{2}+\beta_{f i x, f i x}\left(l_{i t}^{f i x}\right)^{2} \\
& +\beta_{t e m p, t e m p}\left(l_{i t}^{t e m p}\right)^{2}+\beta_{f i x, t e m p} l_{i t}^{f i x} l_{i t}^{\text {temp }}+\beta_{k, f i x} k_{i t} l_{i t}^{f i x}+\beta_{k, t e m p} k_{i t} l_{i t}^{t e m p}+\varepsilon_{i t}
\end{aligned}
$$

The output elasticity in this case is derived as:

$$
\begin{aligned}
\theta_{i t}^{t e m p} & =\frac{\partial q_{i t}}{\partial l_{i t}^{t e m p}} \\
& =\beta_{t e m p}+2 \beta_{t e m p, t e m p} l_{i t}^{t e m p}+\beta_{f i x, t e m p} l_{i t}^{f i x}+\beta_{k, t e m p} k_{i t}
\end{aligned}
$$


The markup in the first setup can only be calculated for firms that have temporary contract employees. Since large firms are more likely to hire temporary contract employees, this case is estimated on a subset of firms that covers the majority of total output.

The second main setup is a gross output (GO) production function:

$$
q_{i t}=\beta_{0}+\beta_{k} k_{i t}+\beta_{l} l_{i t}+\beta_{m} m_{i t}+\varepsilon_{i t}
$$

We consider materials as the only free input and include wages as an instrument. The relevant output elasticity is:

$$
\theta_{i t}^{M}=\frac{\partial q_{i t}}{\partial m_{i t}}=\beta_{m}
$$

The expressions of the Translog case are simply obtained by replacing $l_{i t}^{f i x}$ by $l_{i t}$ and $l_{i t}^{\text {temp }}$ by $m_{i t}$ in (6) and (7).

\section{Data}

We construct a firm-level dataset that includes all non-financial firms that pay corporate tax in the Netherlands, covering the period 2006-2016. The advantage of the dataset is that it combines firm and employee level statistics and therefore offers a comprehensive set of firm level variables.

The data used in the analysis are based on three datasets obtained from Statistics Netherlands (or CBS). Firstly, the business registry (ABR) dataset contains basic background statistics such as firm birth date, sector and size. Due to major changes in the ABR in 2006, we consider data in the period 2006-2016, giving an unbalanced panel of 11 years. Secondly, the non-financial firms (NFO) dataset contains book value data of Dutch firms. The NFO data are, in Statistics Netherlands terminology, at the enterprise level. ${ }^{7}$ An enterprise can contain multiple firms. In most cases, however, the enterprise is equal to one firm. ${ }^{8}$ The ABR lists to which enterprise each firm belongs. Thirdly, the Polisbus dataset contains employee level data. We add labour hours obtained from Polisbus, which are split into fixed and flexible contract hours enabling us to experiment with an improved measure of free input.

The NFO dataset is at the enterprise level and the Polisbus data is at the employee level. This means that when only some of the firms that comprise the enterprise have employee data, merging the two datasets results in a partial match (around 2.0\% of the firm-year observations).

\footnotetext{
${ }^{7}$ According to the documentation of Statistics Netherlands, NFO covers $80 \%$ of the large enterprises and $90 \%$ to $95 \%$ of the small enterprises (in terms of the balance sheet total).

${ }^{8}$ In the dataset used in this study, $95.5 \%$ of the enterprises consist of only one firm. The majority $(77.2 \%)$ of the observations where an enterprise consists of multiple firms appear in the 2006-2009 subsample.
} 
When matched employment data account for less than $90 \%$ of the total employment in fulltime equivalents (ftes) for the enterprise, we delete the enterprise from the sample $(33.5 \%$ of the partial matches). This results in keeping on average $84.2 \%$ of the firms observations each year. The match results in the greatest loss for small enterprises $(10.5 \%$ of the enterprise observations). A large part (43.1\%) of the loss of small firms is due to enterprises that have only one part-time employee with less than $0.5 \mathrm{fte}$. For larger enterprises (20 fte) the loss is minimal, as only $3.5 \%$ of the enterprise observations do not have corresponding labour hours data.

The SVA approach can only be applied to firms that have temporary contract employment. A relatively large percentage of firms, ranging from a minimum of $36 \%$ to a maximum of $44 \%$, have temporary contract employees in a certain year. The fraction of temporary contract hours in total hours ranges on average between a minimum of $11.2 \%$ to a maximum of $21.2 \%$ per year, indicating that temporary contract employees work a modest share of the total hours worked within a firm. The wage of temporary contract employees is also lower (on average $€ 14.1$ per hour) than that of fixed contact employees (on average $€ 21.0$ per hour). The selection of firms with temporary contract employment is not random as they tend to be much larger than other firms. The median employment of a firm with temporary contract workers is $7 \mathrm{fte}$, while the median employment of firms without temporary contract employment is 1 fte. ${ }^{9}$ However, the SVA approach captures the majority of output, on average $87.2 \%$ of total firm output.

Table 1 shows the descriptives of the main variables for the total database and the subsamples used for the two setups GO and SVA. ${ }^{10}$ The subsample used for the GO analysis is somewhat smaller, but resembles the total database. The subsample used for the SVA is much smaller with a larger share of large firms (including MNEs) in terms of employment and capital.

\section{Results}

\subsection{Evidence for stable markups}

The revenue weighted sample average of the markup is similar within the different setups (see Table 2). The average markup is estimated to be higher than 1 and has a distribution that contains plausible values. ${ }^{11}$ The average markup is higher in the SVA case, which is probably

\footnotetext{
${ }^{9}$ The mean employment is $33.0 \mathrm{fte}$ and $3.2 \mathrm{fte}$, respectively.

${ }^{10}$ For a complete list of the variables used see Appendix table A.2.

${ }^{11}$ The estimated coefficients of the production function have to be positive (in the translog case, the mean output elasticity has to be positive). Two sectors gave implausible estimates (negative coefficients) and are excluded from the analysis: sector 51 (Air transport) and 15 (Manufacture of leather, leather goods and shoes).
} 
Table 1: Descriptives of main variables in the different setups

\begin{tabular}{|c|c|c|c|c|c|c|}
\hline & \multicolumn{2}{|l|}{ Total } & \multicolumn{2}{|l|}{ GO } & \multicolumn{2}{|l|}{ SVA } \\
\hline & mean (s.d.) & $\mathrm{N}$ & mean (s.d.) & $\mathrm{N}$ & mean (s.d.) & $\mathrm{N}$ \\
\hline \multirow[t]{2}{*}{ Employment } & 14.7 & 250511 & 15.7 & 205211 & 33.1 & 91267 \\
\hline & (351.9) & & (370.7) & & 555.1 & \\
\hline \multirow[t]{2}{*}{ Capital } & 1873.5 & 207425 & 1889.5 & 205211 & 3836.1 & 91267 \\
\hline & (66191.1) & & $(66540.7)$ & & (99264.2) & \\
\hline \multirow[t]{2}{*}{ Turnover } & 5603.9 & 207425 & 5662.1 & 205211 & 11526.9 & 91267 \\
\hline & (115025.3) & & (115642.7) & & ( 152587.0$)$ & \\
\hline \multirow[t]{2}{*}{ Profit rate } & $9.2 \%$ & 203117 & $8.8 \%$ & 201414 & $4.9 \%$ & 90725 \\
\hline & $(61.1 \%)$ & & $(60.4 \%)$ & & $(35.3 \%)$ & \\
\hline \multirow[t]{2}{*}{ Age } & 9.1 & 250507 & 9.2 & 205207 & 10.6 & 91267 \\
\hline & $(7.2)$ & & (7.5) & & $(7.2)$ & \\
\hline Share of MNEs & $3.4 \%$ & & $4.1 \%$ & & $6.7 \%$ & \\
\hline
\end{tabular}

due to the sample of larger firms. The SVA markups have a relatively tight distribution where most markups fall into a plausible range of values. In the Cobb-Douglas case in the GO setup, the range of markup values is wider and markups lower than 1 are more frequently encountered. The Translog case is discussed later.

Figure 2 shows that the weighted average markup in the Cobb-Douglas case is relatively stable between 2006 and 2016. After a similar development, both setups result in a decrease in markups of around $4 \%$ by 2016 compared to 2006 . The SVA markup initially decreases, then recovers in 2009 and 2010, to drop to its lowest level in 2012.

The different percentiles of the weighted markup distribution also give no indication of increasing markups in the Netherlands (see Figure 3). The markups of the SVA approach in the bottom decile remain close to the 2006 value, while the median and top deciles show a small decrease over time. The GO percentiles show quite a different pattern over time. Here the top decile shows the smallest decrease $(2.5 \%)$ while the bottom decile shows the largest decrease $(12.1 \%)$. The differences between these setups are probably due to the smaller sample consisting of larger firms for the SVA approach. Nonetheless, all percentiles show a decrease in the markup, which contradicts the two main results found in most of the recent literature.

Both sectors contain relatively few firms, which is probably the reason why the estimation is problematic. There are 51 sectors that remain in the final analysis. There are three sectors (SBI 26, 30 and 32) for which a second order polynomial proxy was used instead of a third order polynomial proxy in the SVA case due to estimation difficulties related to a low number of observations. The results are robust to the exclusion of these sectors. 
Table 2: Weighted average markup

\begin{tabular}{lc}
\hline & mean (sd) \\
\hline $\begin{array}{l}\text { Setup } 1 \text { Structural value added } \\
\text { Cobb-Douglas }\end{array}$ & $1.29(0.54)$ \\
Translog & $1.23(0.39)$ \\
Setup 2 Gross output & \\
Cobb-Douglas & $1.11(1.14)$ \\
Translog & $1.09(0.44)$ \\
\hline $\begin{array}{l}\text { Note: The 1st and 99th percentiles of the markup distribu- } \\
\text { tion have been truncated for each method. The markups are } \\
\text { weighted with revenue. The markup mean is calculated as the } \\
\text { average of the weighted average markup calculated for each } \\
\text { year. }\end{array}$
\end{tabular}

Figure 2: Average weighted markups in Cobb-Douglas case $(2006=1)$

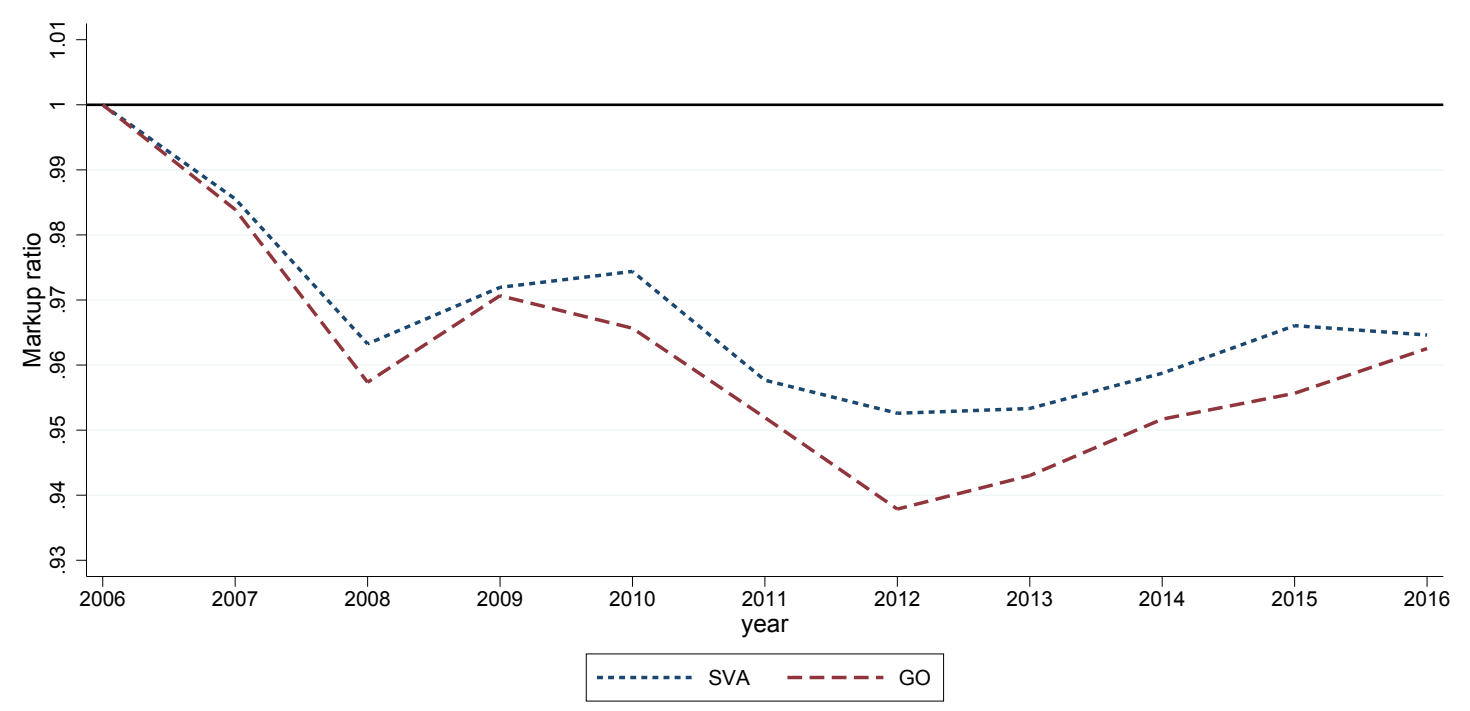

Notes: The 1st and 99th percentile of the markup distribution have been truncated for each method. The markups are weighted with revenue.

Firstly, markups are showing a rather stable (or even slightly decreasing) trend and secondly, the top decile does not show an increasing trend.

In van Heuvelen et al. (2019) we report markups per sector. We find that only two out of the 51 sectors show increasing markups. ${ }^{12}$ The remaining sectors show no evidence of markups

\footnotetext{
${ }^{12}$ Manufacturing of pharmaceutical raw materials and products (SBI 21) and Travel mediation, travel organization, tourist information and reservation agencies (SBI 79).
} 
Figure 3: Markups in CD-case of percentiles in the weighted distribution $(2006=1)$

a. SVA

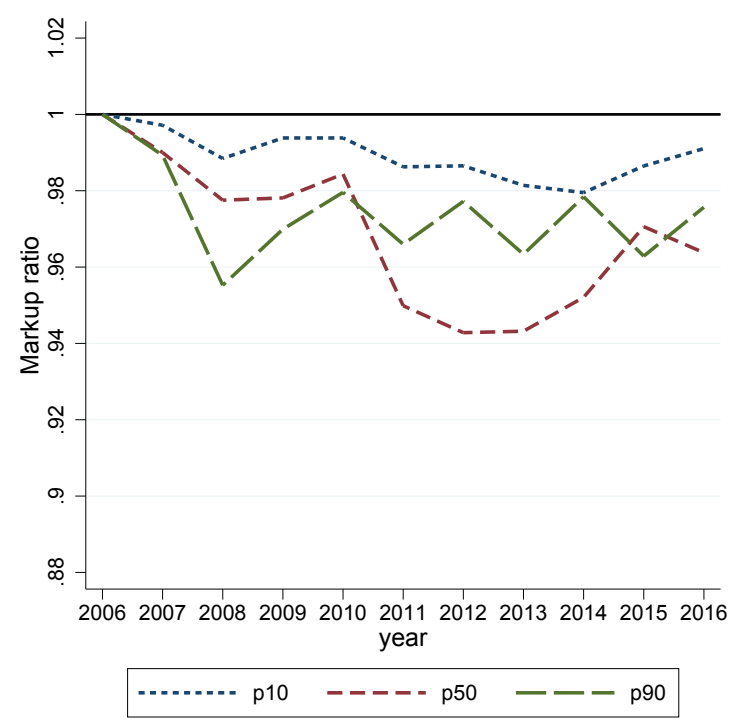

b. GO

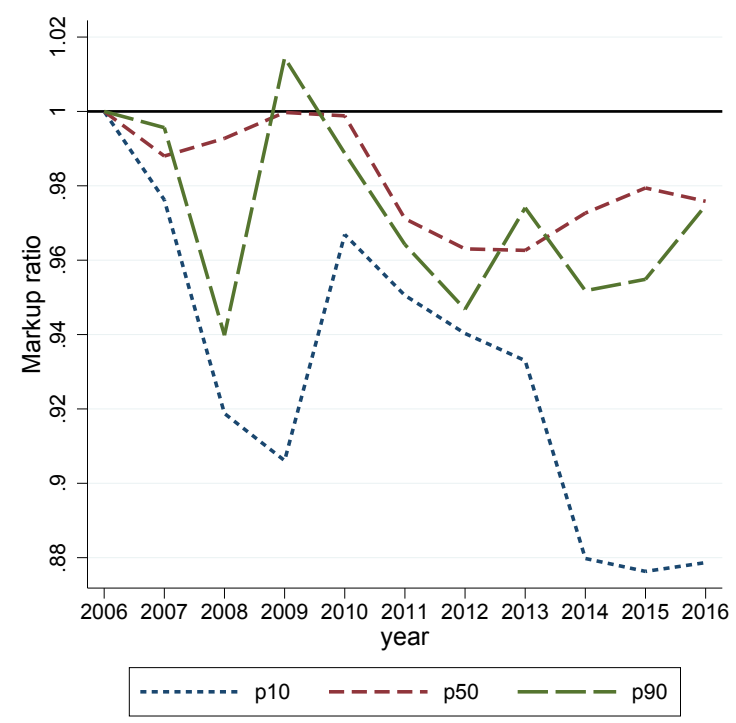

Notes: The 1st and 99th percentiles of the markup distribution have been truncated. The markups are weighted with revenue.

that are (rapidly) increasing.

\subsection{Sensitivity to the choice of the free input}

If we choose a fixed variable as free input in the production function approach, the estimation results in increasing markups. First, when we take fixed contract hours as the free variable in the SVA case, we get in Figure 4 slightly increasing markups at the end of the period. The increase after 2012 is driven by the top decile.

Second, when we take total labour hours as free variable in the gross output case, we get both implausible markup levels and a rapidly increasing trend over time (the average level is 10.1 and the increase is $138 \%$ over 2006-2016). Most of this increase happens after 2012 , after which the markup increases by $63 \%$ within four years. This development is driven by a large increase by the top decile of the weighted markup distribution. We confirm that an improper choice of the free input changes the conclusions of the markup trend.

The different results are easily understood when looking at the different developments of the cost share of the free input. Recall from equation (2) that the markup is calculated as the ratio of the output elasticity and the cost share of the free input. Since in all cases, the change in the average output elasticity remains limited, the variation of the markup over time 
Figure 4: Average weighted markup in CD-case $(2006=1)$

a. Fixed contract hours

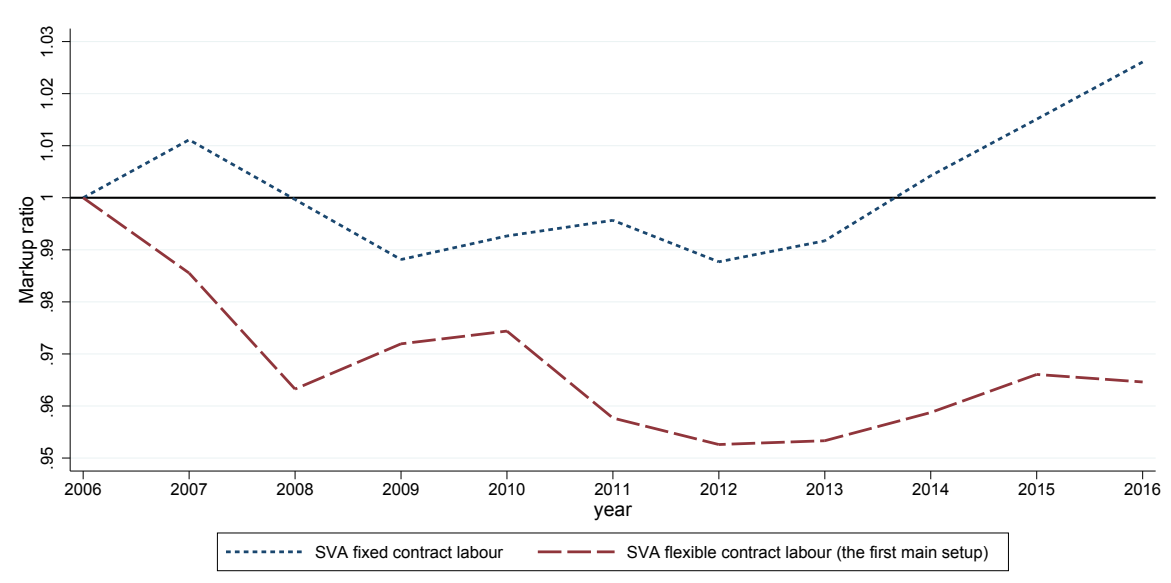

b. Labour

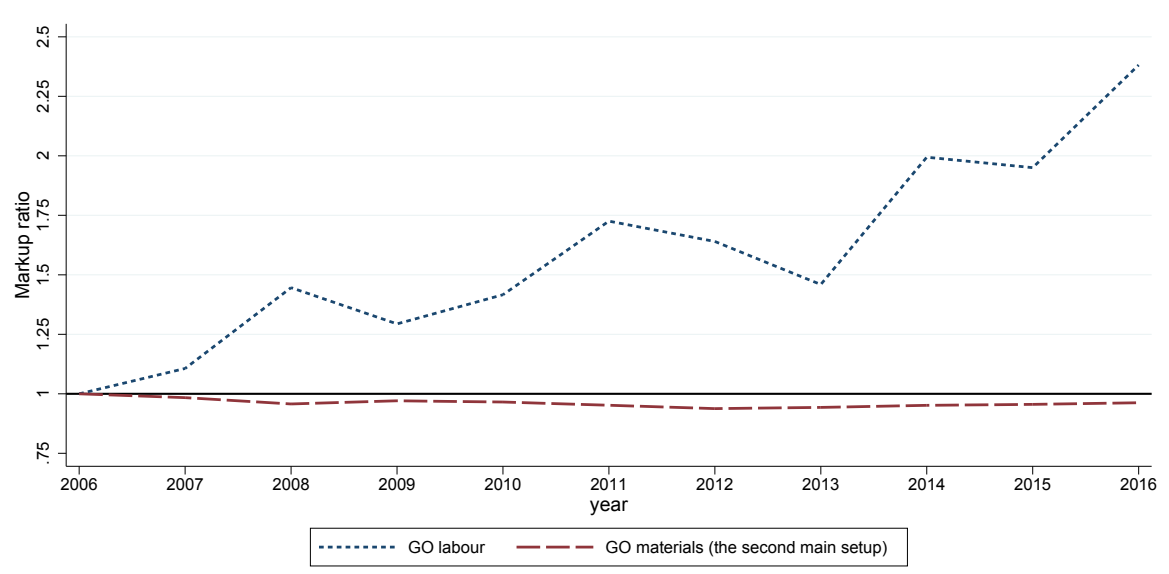

Notes: The 1st and 99th percentiles of the markup distribution have been truncated for each method. The markups are weighted with revenue. The weighted average markup for GO (SVA) approach with (fixed) labour as free variable is 6.40 (1.07) in 2006.

is mainly driven by the development of the cost share of the free input: a rising cost share results in a decreasing markup. ${ }^{13}$ In our sample, the output weighted share of total labour costs decreases over time. This decrease is driven by a reduction of the share of fixed labour costs (from $10.1 \%$ to $8.7 \%$ ), while the cost share of temporary labour slightly increases over time (from $2.0 \%$ to $2.8 \%$ ). The material cost share increases from $74.8 \%$ to $76.2 \%$. The cost shares of the preferred free inputs show an increasing trend, hence will have a decreasing effect

\footnotetext{
${ }^{13}$ De Loecker et al. (2020) also show that in the US the main driver of the markup is the cost share.
} 
on markups. Fixed labour shows a decreasing trend, and will lead to an increasing markup.

The different mix of free and fixed variables may also explain the differences with De Loecker and Eeckhout (2018a), which is the only study that reports markups for the Netherlands. They use a small sample of large firms contained in Worldscope. In contrast to our study, they report a steep increase of the markup. ${ }^{14}$ Restricted by the dataset, De Loecker and Eeckhout (2018a) use the costs of goods sold (COGS) as free input, while we use flexible labour or material inputs. The COGS in Worldscope is a broad concept that contains the costs of both labour and materials but also the cost of rent and royalty incomes. If fixed costs are included in the COGS, this could drive the increase over time (see De Loecker and Eeckhout, 2018b). Our data show that the share of total labour costs display a decreasing trend, in particular for large firms. Including fixed labour and other fixed costs in the free variable might contribute to estimating a different trend in markups.

\subsection{Translog}

When we use a Translog production function, the results remain similar. ${ }^{15}$ The results for the Translog case of the SVA approach are very similar to those found in the Cobb-Douglas case (Figure 5). The markup in 2016 is again estimated to be $3.6 \%$ below the 2006 value. The Translog GO case does display a different trend: the markup remains close to the 2006 value until 2013 after which it slightly rises. The markup in 2016 is $3.4 \%$ higher than the markup in 2006, but this rise is still much smaller than found in other papers.

The percentiles of the Translog weighted markup distribution also show a slightly different pattern over time. Both the bottom and top deciles of the SVA Translog distribution remain relatively close to their 2006 value, except for the hike in 2009. The median markup shows a decreasing trend until 2012, after which it increases. All percentiles end up below their starting values. In the GO Translog case, the top decile and median show an increasing trend, while the bottom decile shows a decreasing trend. The slight average rise is therefore driven by the upper half of the markup distribution and not only by the top decile.

In sum, our results point to very stable markups over the 2006-2016 period. Even the underlying dynamics of the weighted distribution do not show large increases; the top decile shows no sign of increasing markups.

\footnotetext{
${ }^{14}$ van Heuvelen et al. (2019) show that this finding is highly sensitive to the applied outlier strategy.

${ }^{15}$ Compared to a Cobb-Douglas production function, the number of observations is lower when using a Translog production function because more negative markups need to be excluded from the analysis. We lose $9.1 \%$ of the SVA sample and $22.8 \%$ of the GO sample.
} 
Figure 5: Average weighted markups over time $(2006=1)$ for Translog

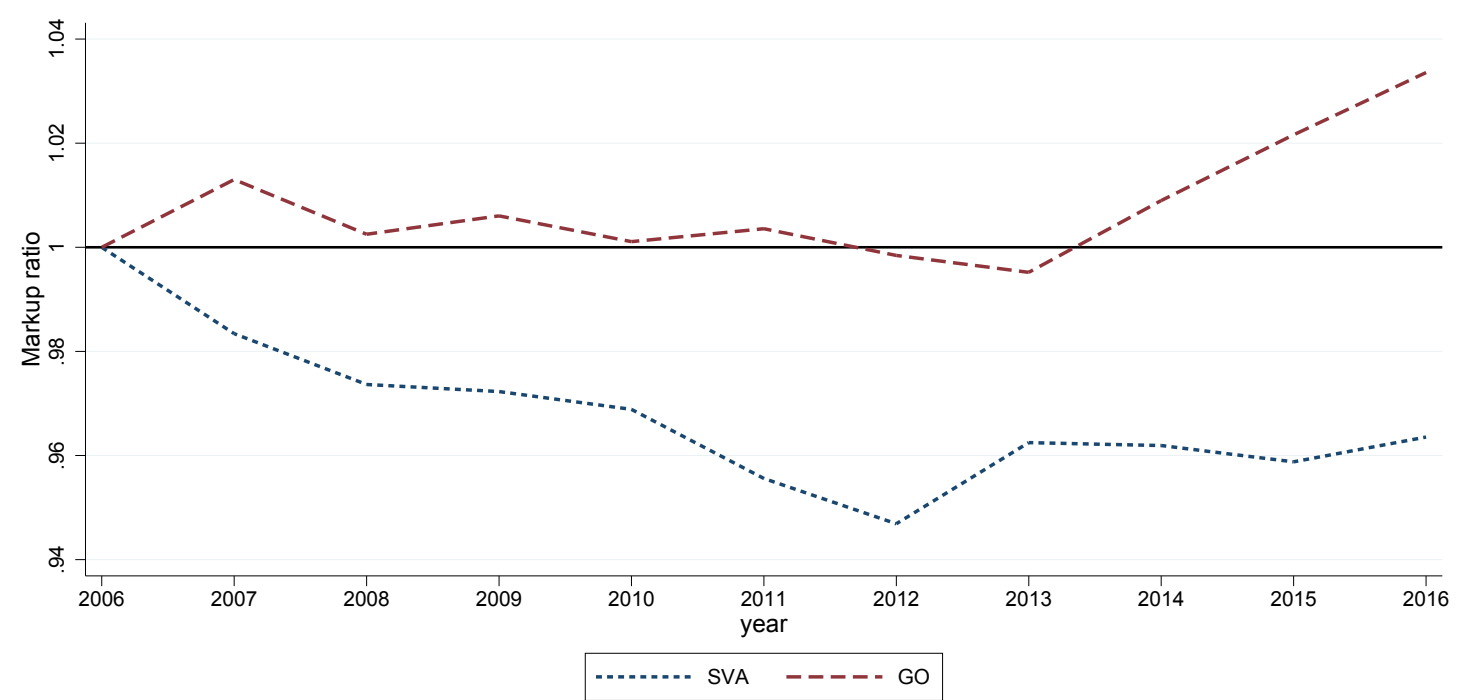

Notes: The 1st and 99th percentiles of the markup distribution have been truncated for each method. The markups are weighted with revenue.

Figure 6: Markups in Translog case of percentiles in the weighted distribution $(2006=1)$

a. SVA

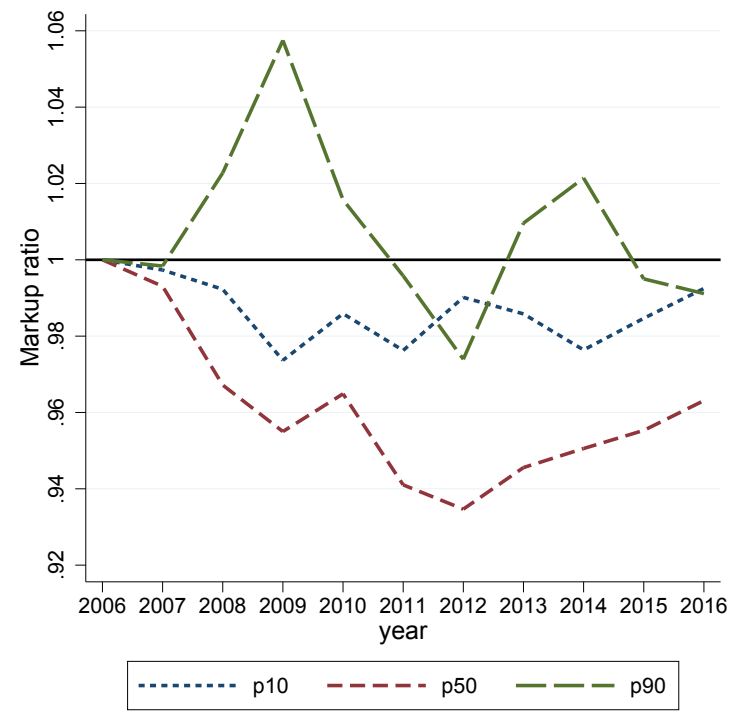

b. GO

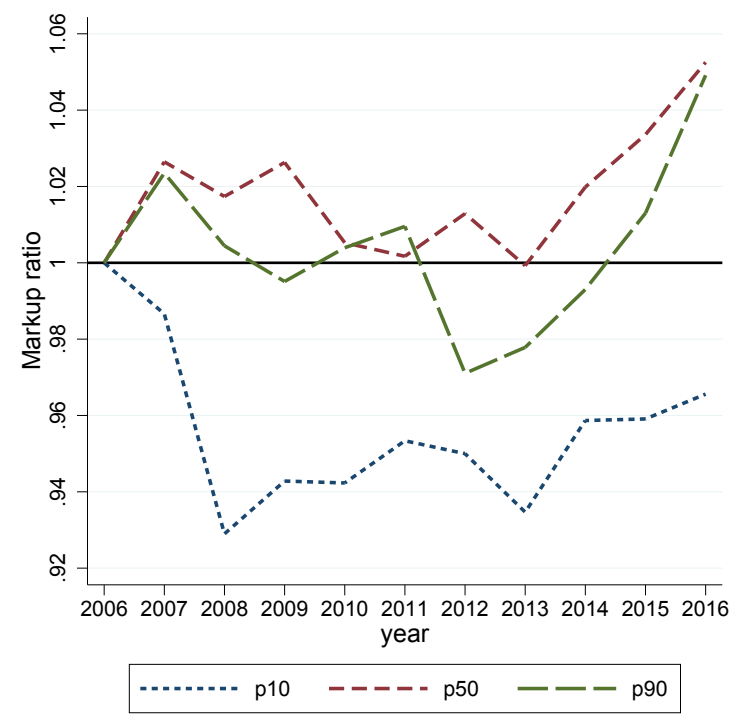

Notes: The 1st and 99th percentiles of the markup distribution have been truncated for each method. The markups are weighted with revenue. 


\subsection{Stability of the markup distribution over time}

Calligaris et al. (2018) raise the question whether it is the same firm that charges high markups over time. We answer this question by computing one-year transition matrices. Firms are first ranked in terms of their markups in the starting year and then divided into deciles per sector. The same is done for the next year. The transition matrix shows how firms move across markup deciles from one year to the next.

Table 3: Transition matrix SVA markups

\begin{tabular}{|c|c|c|c|c|c|c|c|c|c|c|c|}
\hline & D1 & D2 & D3 & D4 & D5 & D6 & D7 & D8 & D9 & D10 & Exit Rate \\
\hline D1 & 61.9 & 20.3 & 6.3 & 3.2 & 2.0 & 1.4 & 1.1 & 0.8 & 1.0 & 2.0 & 22.7 \\
\hline D2 & 16.5 & 41.0 & 21.6 & 8.7 & 4.4 & 2.4 & 1.6 & 1.1 & 1.1 & 1.5 & 17.2 \\
\hline D3 & 5.2 & 18.9 & 33.0 & 20.8 & 9.8 & 4.8 & 2.8 & 1.8 & 1.4 & 1.5 & 15.6 \\
\hline D4 & 2.6 & 7.5 & 19.0 & 30.3 & 19.8 & 9.7 & 4.7 & 2.8 & 2.0 & 1.7 & 15.0 \\
\hline D5 & 1.8 & 3.8 & 8.2 & 18.5 & 28.8 & 19.7 & 9.5 & 4.7 & 2.9 & 2.1 & 14.7 \\
\hline D6 & 1.4 & 2.2 & 4.3 & 8.5 & 18.3 & 29.9 & 19.6 & 8.8 & 4.4 & 2.5 & 14.2 \\
\hline D7 & 1.0 & 1.5 & 2.4 & 4.1 & 8.6 & 18.8 & 32.6 & 19.5 & 7.9 & 3.5 & 14.3 \\
\hline D8 & 0.9 & 1.1 & 1.7 & 2.5 & 4.3 & 8.0 & 19.1 & 37.3 & 19.4 & 5.8 & 14.9 \\
\hline D9 & 1.0 & 1.1 & 1.3 & 1.9 & 2.6 & 4.0 & 7.3 & 19.0 & 45.2 & 16.4 & 16.8 \\
\hline D10 & 2.0 & 1.5 & 1.5 & 1.8 & 2.1 & 2.5 & 3.5 & 5.8 & 17.6 & 61.7 & 26.8 \\
\hline
\end{tabular}

Note: For the transition matrix the firms are ranked in terms of SVA markups in year $t$ and sector $\mathrm{i}$ and then divided into deciles. The same is done for the year $t+1$. The transition matrix shows how firms move over markup deciles, when going from one year to the next. D10 is the decile with the highest markups and D1 is the decile with the lowest markups. The transition probabilities are the average one-step transition rates over all years. The exit rate indicates the percentage of firms that exit the sample when going from year $t$ to year $t+1$.

The average transition matrix in Table 3 for the SVA-case shows that it is often the same firms that charge high markups, from one year to the next, but also often the same firms that charge low markups. Putting it differently, firms in the highest and lowest markup deciles are most likely to remain within the same decile, conditional on survival. The low transition rates to deciles located far away from the initial decile a firm is located indicate stability. We find that $74.5 \%$ of the firms remain in the same decile or move one decile higher or lower from one year to the next (i.e. these are the firms found in the red cells).

The exit rate in the last column of Table 3 gives the fraction of firms for which a markup could not be calculated in the next year. This could be due to different reasons: merger and acquisitions, restructuring and bankrupties or firing all flexible labour. The exit rate is also the highest in the top and bottom markup deciles. 


\subsection{The relationship between markups and profits}

High markups do not necessarily imply higher profit rates. When a firm incurs higher fixed costs, the markup will rise to recover the fixed cost. Figure 7a shows, however, that firms with higher markups also have higher profit rates, indicating that higher markups are not solely driven by fixed costs (as in De Loecker et al., 2020; Barkai, 2017). The results in this figure are for 2015 but a similar pattern holds for other years as well. Furthermore, Figure $7 \mathrm{~b}$ shows that, after a strong drop, the average weighted profit share has stabilised after the Great Recession. The observation that the profit rate shows no increasing trend supports the evidence of stable markups.

Figure 7: Profit share

a. Profit rate per markup decile in 2015

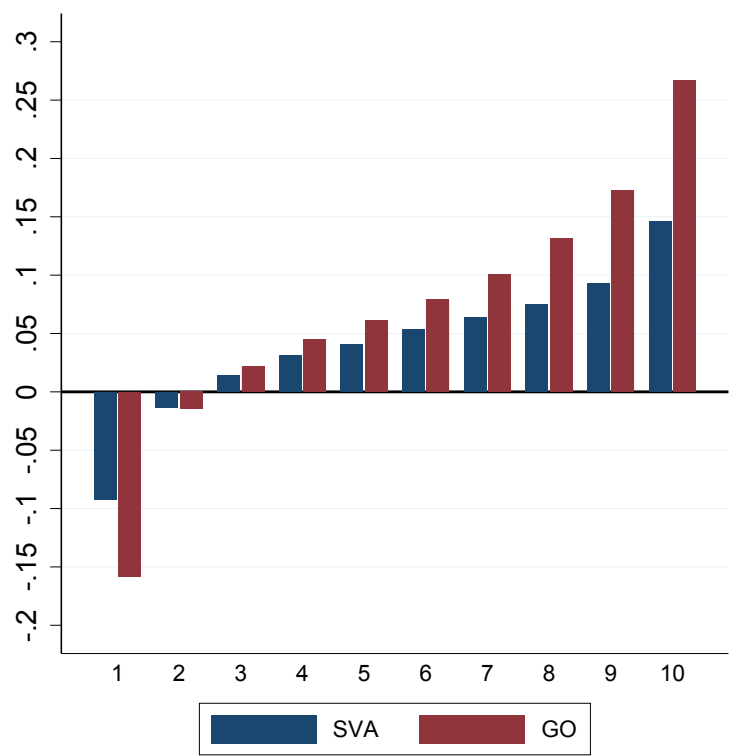

b. Average weighted profit share over time

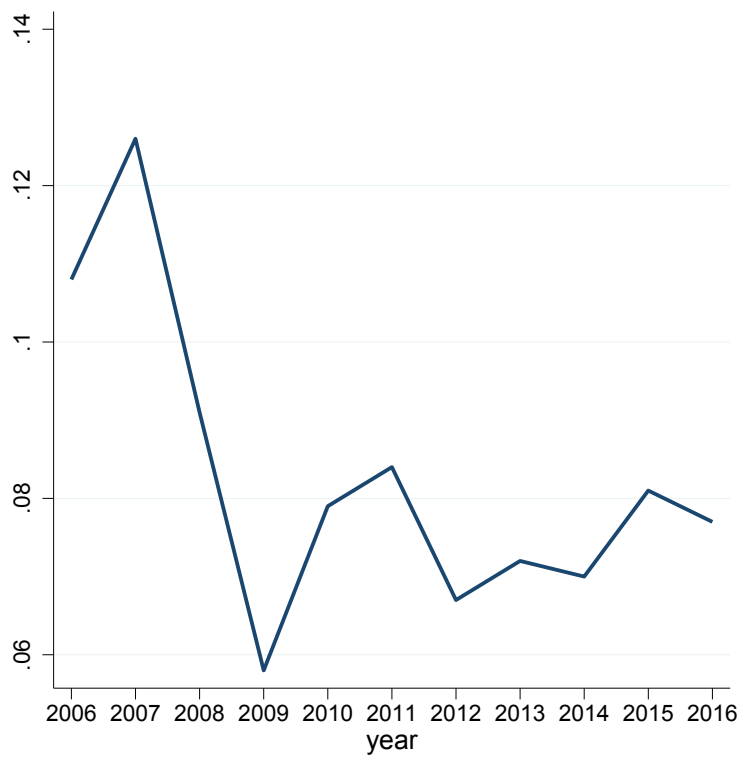

Note: a. Profit share=net profit/total revenue. The markup deciles are created for each sector. Therefore, the highest markup decile contains all the firms belonging to the highest markup decile of their sector. The profit rate displayed is the average profit rate per decile (the median will give a similar picture). b. The profit shares are weighted with revenue.

\subsection{Consolidation}

Another explanation for diverging results for markup estimation may lie in the consolidation level of the accounts of the firms. In our dataset, firms are consolidated at the national level, whereas consolidation in Worldscope (used by for instance De Loecker and Eeckhout, 2018a) is at the international level. A priori, the preferred level of consolidation is not clear. The 
advantage of international consolidation is that mismeasurements of costs of intra-company transactions are avoided. For example, transfer pricing complicates the estimation of markups as revenues and costs will be misreported at a national level. A disadvantage of international consolidation is that it implicitly assumes that labour and/or materials, located in the different countries the multinational produces in, are perfect substitutes (see De Loecker and Eeckhout, 2018a). This approach estimates one production function with combined output and input data of several subsidiaries producing with different technologies and different input mixes, responding to different mixes of prices. Under national consolidation, a production function is estimated for more homogeneous firms within a sector. However, De Loecker et al. (2020) provide evidence for US firms, that the differences in consolidation level do not result in a systematic difference in obtained markup results. They show that the weighted average markup based on international consolidated accounts is within half a percentage point of the average markup based on nationally consolidated data.

\section{Conclusion}

We studied the impact of the free variable on markup estimates with the case of the Netherlands. We show that the choice of the free variable is important and may explain at least some of the discrepancies in the findings of the recent literature. The free variable is key in the production function approach because it determines the trend of the markup. If a variable is chosen that is not strictly free, this will result in a different markup trend. We illustrate this for the Netherlands. When we use the temporary labour hours for the free variable (i.e. excluding fixed contract hours), we obtain stable markups for the period 2006-2016. Using total labour hours results in rapidly increasing markups for the same period.

A second reason for diverging results in the literature may be a result of the dataset used. Studies using a dataset with large (international) firms mostly find increasing markups. With a database that includes all non-financial firms, we find highly stable markups. A fundamental difference between datasets concerns the level of consolidation of the accounts of multinationals. Does the research focus on internationally consolidated multinationals (e.g. using Worldscope) or is it nationally consolidated firms that produce within the country (e.g. using census data)? In the first case, markup estimates include goods and services produced by all the foreign subsidiaries that are owned by the multinational. In the second case, markup estimates include the goods and services that a firm produces within the country. Therefore, the finding that markups of internationally consolidated multinationals are rising might in principle be consistent with the finding that markups of nationally consolidated firms are stable.

Our results have broader implications. First, when measuring markups, the institutional 
features of a country should be taken into account. Labour markets are regulated differently, which translates into different adjustment costs and therefore determines the suitability of labour as a free variable. When labour has high adjustment cost, it cannot be considered a true free variable; not taking this into account may erroneously lead to finding increasing markups. Secondly, it is not a priori clear for which market, the national or the international, markups should be measured; both make sense. Different results might tentatively be attributed to transfer pricing of intra-company transactions. We conclude that this is an issue where more research is needed. Finally, recent work on increasing markups have sparked a discussion on possible policy interventions, as it is interpreted as an indication of the lack of competition between firms (see for instance the meeting of central bankers at Jackson Hole in August 2018). This paper shows that policies should be country specific when results are sensitive to country specific conditions.

\section{References}

Ackerberg, D. A., Caves, K., and Frazer, G. (2015). Identification Properties of Recent Production Function Estimators. Econometrica, 83(6):2411-2451.

Autor, D., Dorn, D., Katz, L. F., Patterson, C., and Reenen, J. V. (2017). The Fall of the Labor Share and the Rise of Superstar Firms. Working Paper 23396, National Bureau of Economic Research.

Azar, J., Marinescu, I., and Steinbaum, M. I. (2017). Labor Market Concentration. Working Paper 24147, National Bureau of Economic Research.

Barkai, S. (2017). Declining labor and capital shares. Mimeograph, Univerity of Chicago.

Basu, S. (2019). Are Price-Cost Markups Rising in the United States? A Discussion of the Evidence. Working Paper 26057, National Bureau of Economic Research.

Berry, S., Levinsohn, J., and Pakes, A. (2004). Differentiated products demand systems from a combination of micro and macro data: The new car market. Journal of political Economy, 112(1):68-105.

Calligaris, S., Criscuolo, C., and Marcolin, L. (2018). Mark-ups in the digital era. OECD Science, Technology and Industry Working Papers 2018/10.

Cavalleri, M. C., Eliet, A., McAdam, P., Petroulakis, F., Soares, A., and Vansteenkiste, I. (2019). Concentration, market power and dynamism in the euro area. ECB Working Paper Series No 2253 / March 2019, ECB, Frankfurt am Main. 
De Loecker, J. and Eeckhout, J. (2017). The Rise of Market Power and the Macroeconomic Implications. Working Paper 23687, National Bureau of Economic Research.

De Loecker, J. and Eeckhout, J. (2018a). Global Market Power. Working Paper 24768, National Bureau of Economic Research.

De Loecker, J. and Eeckhout, J. (2018b). Some Thoughts on the Debate about (Aggregate) Markup Measurement. Mimeograph December 6, KU Leuven.

De Loecker, J., Eeckhout, J., and Unger, G. (2020). The Rise of Market Power and the Macroeconomic Implications. The Quarterly Journal of Economics, (Forthcoming).

De Loecker, J., Fuss, C., and Biesebroeck, J. V. (2018). Markup and price dynamics: Linking micro to macro. Technical Report 357, National Bank of Belgium.

De Loecker, J. and Scott, P. T. (2016). Estimating market power Evidence from the US Brewing Industry. Working Paper 22957, National Bureau of Economic Research.

De Loecker, J. and Warzynski, F. (2012). Markups and Firm-Level Export Status. The American Economic Review, 102(6):2437-2471.

Diez, M. F., Leigh, M. D., and Tambunlertchai, S. (2018). Global Market Power and its Macroeconomic Implications. IMF Working Paper 18/137, International Monetary Fund.

Doraszelski, U. and Jaumandreu, J. (2013). R\&D and Productivity: Estimating Endogenous Productivity. The Review of Economic Studies, 80(4):1338-1383.

Flynn, Z., Gandhi, A., and Traina, J. (2019). Identifying market power from production data. Technical report, Working paper.

Gandhi, A., Navarro, S., and Rivers, D. (2017). How Heterogeneous is Productivity? A Comparison of Gross Output and Value Added.

Gutiérrez, G. and Philippon, T. (2016). Investment-less Growth: An Empirical Investigation. Working Paper 22897, National Bureau of Economic Research.

Gutiérrez, G. and Philippon, T. (2017). Declining Competition and Investment in the U.S. Working Paper 23583, National Bureau of Economic Research.

Gutiérrez, G. and Philippon, T. (2018). How EU Markets Became More Competitive Than US Markets: A Study of Institutional Drift. Working Paper 24700, National Bureau of Economic Research. 
Hall, R. E. (1988). The Relation between Price and Marginal Cost in U.S. Industry. Journal of Political Economy, 96(5):921-947.

Hall, R. E. (2018). New Evidence on the Markup of Prices over Marginal Costs and the Role of Mega-Firms in the US Economy. Working Paper 24574, National Bureau of Economic Research. DOI: 10.3386/w24574.

Karabarbounis, L. and Neiman, B. (2018). Accounting for Factorless Income. Working Paper 24404, National Bureau of Economic Research.

Levinsohn, J. and Petrin, A. (2003). Estimating Production Functions Using Inputs to Control for Unobservables. The Review of Economic Studies, 70(2):317-341.

OECD (2020a). Employment - Temporary employment - OECD Data.

OECD (2020b). Strictness of employment protection individual dismissals (regular contracts).

Olley, G. S. and Pakes, A. (1996). The Dynamics of Productivity in the Telecommunications Equipment Industry. Econometrica, 64(6):1263-1297.

Traina, J. (2018). Is Aggregate Market Power Increasing? Production Trends Using Financial Statements. New Working Paper Sereis no. 17, Stigler Center Chicago Booth.

van Heuvelen, G. H., Bettendorf, L., and Meijerink, G. (2019). Estimating Markups in the Netherlands. Background Document March, CPB Netherlands Bureau for Economic Policy Analysis, The Hague.

Van Reenen, J. (2018). Increasing differences between firms: Market power and the macroeconomy. CEP Discussion Papers CEPDP1576), Centre for Economic Performance, London School of Economics and Political Science, London, UK.

Weche, J. P. and Wambach, A. (2018). The fall and rise of market power in Europe. ZEW Discussion Papers 18-003, Leibniz-Zentrum für Europäische Wirtschaftsforschung, Mannheim.

Wooldridge, J. M. (2009). On estimating firm-level production functions using proxy variables to control for unobservables. Economics Letters, 104(3):112-114. 


\section{A Appendix}

Table A.1: Percentage of NFO enterprises that match with Polisbus data

\begin{tabular}{l|lllllllllll|l}
\hline & 2006 & 2007 & 2008 & 2009 & 2010 & 2011 & 2012 & 2013 & 2014 & 2015 & 2016 & mean \\
\hline Partial Match & 88.6 & 88.0 & 84.7 & 82.7 & 88.5 & 88.1 & 86.9 & 86.1 & 85.0 & 84.4 & 85.0 & 86.2 \\
Match with & 86.8 & 85.6 & 83.4 & 81.4 & 88.4 & 88.1 & 86.9 & 86.0 & 85.0 & 84.4 & 85.0 & 85.5 \\
$\begin{array}{l}\text { diff. }<10 \% \\
\text { Full Match }\end{array}$ & 83.5 & 83.3 & 79.5 & 77.4 & 88.0 & 87.8 & 86.7 & 85.9 & 84.8 & 84.2 & 84.8 & 84.2 \\
\hline
\end{tabular}

Note: Matched to an NFO enterprise does not automatically imply that this enterprise also has information on the other variables needed to estimate markups. The firms have to have a balance sheet total that is not missing to be included in this table. The values of 2016 are still under revision at the time of reporting. 
Table A.2: Variable definitions

Output variable

\begin{tabular}{ll}
\hline $\begin{array}{l}\text { Revenues } \\
\text { Value added }\end{array}$ & $\begin{array}{l}\text { Net sales minus returned goods, payed damages and discounts } \\
\text { Revenues }- \text { Materials }\end{array}$ \\
\hline Labour & \\
\hline Labour hours & Number of payed working hours \\
Labour costs & Wages and social security contributions \\
Wage & Gross salary
\end{tabular}

Capital

Capital stock

Tangible fixed assets + Intangible assets - Depreciation

Tangible fixed assets

These are the physical assets intended for the sustainable support of a company's business operations (end of period and before depreciation).

Examples: buildings, machines, installations, computers, transport equipment.

Intangible fixed assets An identifiable non-monetary asset without physical form used for the production and delivery of goods or services, rental to third parties or for administrative purposes (end of period and before depreciation).

Examples: licenses, patents, goodwill.

Depreciation Accounting for impairment resulting from wear and tear (e.g. buildings, machinery, inventory), price drops (e.g. stocks) or other causes. In the dataset it is not possible to separate depreciation of tangible and intangible assets.

Other variables

Materials (i.e. This concerns the (raw) material consumption and the purProduction costs)

Investment chase value of the commodities and other operating expenses included in net sales. Other operating expenses include all costs, insofar as they do not relate to wages, depreciation and interest expenses.

Deflator capital $_{t}-$ capital $_{t-1}+$ depreciation $_{t}$ The nominal values of the variables are deflated by the appropriate sector prices obtained from the input-output tables from the national accounts. We use the following variables to construct a deflator.

1. The capital deflator uses gross fixed capital formation.

2. The value added deflator uses gross value added in basic prices.

3. The labour cost deflator uses wages and employer social security contributions.

4. The revenue deflator uses total revenues.

5. The materials deflator uses consumption at purchasing price.

All the inputs and outputs are in terms of 2010 prices. 